\title{
Leukokinetic Studies. XI. Blood Granulocyte Kinetics in Polycythemia Vera, Infection, and Myelofibrosis *
}

\author{
J. W. Athens, $\dagger$ O. P. HaAb, S. O. RaAb, D. R. Boggs, $\$$ H. Ashenbrucker, \\ G. E. Cartwright, and M. M. Wintrobe \\ (From the Department of Medicine, University of Utah School of Medicine, \\ Salt Lake City, Utah)
}

Although it seems evident that the neutrophilic leukocytosis commonly encountered in patients with purulent infections, polycythemia rubra vera, and a variety of other clinical disorders probably indicates an increased mass of neutrophils in the blood and increased neutrophil production, turnover, and utilization, it has not been possible to quantify these processes directly until recently. In normal subjects it was demonstrated that approximately one-half of the neutrophilic granulocytes in the blood are circulating freely [circulating granulocyte pool (CGP)], whereas the remainder adhere to the walls of small venules [marginal granulocyte pool (MGP)] (1). Since these two pools were shown to be in rapid equilibrium with each other they may be considered to form a single total blood granulocyte pool (TBGP) for kinetic purposes. These facts together with the finding that neutrophilic granulocytes disappear from the blood in a random manner (2) have made it possible to approximate the rate of production and destruction of neutrophils in normal man.

In the present study the size of the TBGP, the distribution of cells in the two subcompartments, the CGP and the MGP, the blood granulocyte half disappearance time $\left(t_{\frac{1}{2}}\right)$, and the granulocyte turnover rate (GTR) were measured in patients with polycythemia vera, myelofibrosis, chronic infections, and diseases of other kinds. Studies in patients with chronic myelocytic leukemia are the

\footnotetext{
* Submitted for publication November 9, 1964; accepted January 14, 1965.

This investigation was supported by a research grant (AM-04489) and a graduate training grant (2A-5098) from the National Institute of Arthritis and Metabolic Diseases, Bethesda, Md.

$\dagger$ Address requests for reprints to Dr. J. W. Athens, Department of Internal Medicine, Salt Lake County General Hospital, 175 East 21st South St., Salt Lake City, Utah 84115.
}

$\ddagger$ Leukemia Society Scholar. subject of a separate report (3). We sought to determine whether there is a characteristic granulocyte kinetic pattern in any of these diseases and whether the observed granulocytosis reflects an absolute increase in TBGP size, an intravascular redistribution of cells, or some combination thereof. In addition an elevated GTR was encountered in many of these studies, and the mechanism by which this is sustained was evaluated. Several preliminary reports of these studies have been published $(4,5)$.

\section{Methods}

Sixty studies were carried out in patients with the disorders mentioned. All patients were studied by means of the in vitro diisopropyl fluorophosphate (DFP ${ }^{32}$ ) granulocyte labeling technic (2). TBGP size was measured by the isotope dilution principle and calculated in two ways. The "determined" TBGP was calculated from the mean of triplicate blood granulocyte radioactivity values obtained 5 minutes after completion of the infusion $\left(t_{0}\right)$. The "extrapolated" TBGP was calculated from the blood granulocyte radioactivity at to obtained by extrapolating the blood granulocyte disappearance curve back to the ordinate. Since the determined TBGP appears to be the more accurate value (3), only these values are given in the tables. The sizes of the CGP and the MGP were determined as previously described (1). The $t_{1}$ was obtained from a semilogarithmic graph of the blood granulocyte specific activity (BGSA) ${ }^{1}$ curve. The GTR was calculated from the TBGP and $t_{1}$ measurements as described previously (6).

Since it is extremely difficult to evaluate kinetic parameters measured in a nonsteady state, only studies on subjects with stable absolute granulocyte counts (less than $20 \%$ variation in most studies and less than $53 \%$ in all studies) and a stable clinical course are included in the evaluations presented here (Tables II, III, IV, and V).

Repeated leukocyte and 200 cell differential counts were done on each patient while under study. The differential counts in these subjects were characterized by relatively little shift to the left with the exception of

\footnotetext{
1 Expressed as counts per minute per milligram granulocyte nitrogen.
} 
four studies in patients with myelofibrosis (Table V). In 18 of the 56 studies 0.5 to $2.5 \%$ myelocytes were found. Metamyelocytes were present in the blood of most of the patients, but in only six were as many as 5 to $9.5 \%$ of these forms present. The remainder of the neutrophils were segmented or juvenile forms. A patient was considered to have granulocytosis if his absolute granulocyte count exceeded 7,500 per $\mathrm{mm}^{3}$ (7).

\section{Results}

Types of blood granulocyte radioactivity curve encountered. As in studies on patients with chronic myelocytic leukemia (3), the $\mathrm{DFP}^{32}$-labeled, granulocyte disappearance curves in these 60 studies were of three types (Figure 1). In 41 studies a single exponential blood granulocyte dis- appearance (type "A") curve was observed. In 12 studies a rapid fall in blood granulocyte specific activity (BGSA) occurred during the first several hours after infusion of the labeled blood. Thereafter the BGSA decline could be described by a single exponential curve, type " $B$ " curve. In seven studies a changing granulocyte disappearance rate was observed and a single $t_{1}$ could not be obtained, type "C" curve. The number of times the several curve types were encountered in the several diseases studied is shown in Table $I$. In type A curves the two TBGP values were the same. In type B curves the extrapolated TBGP values were larger than the determined values. In type C curves no extrapolated TBGP was calculated.

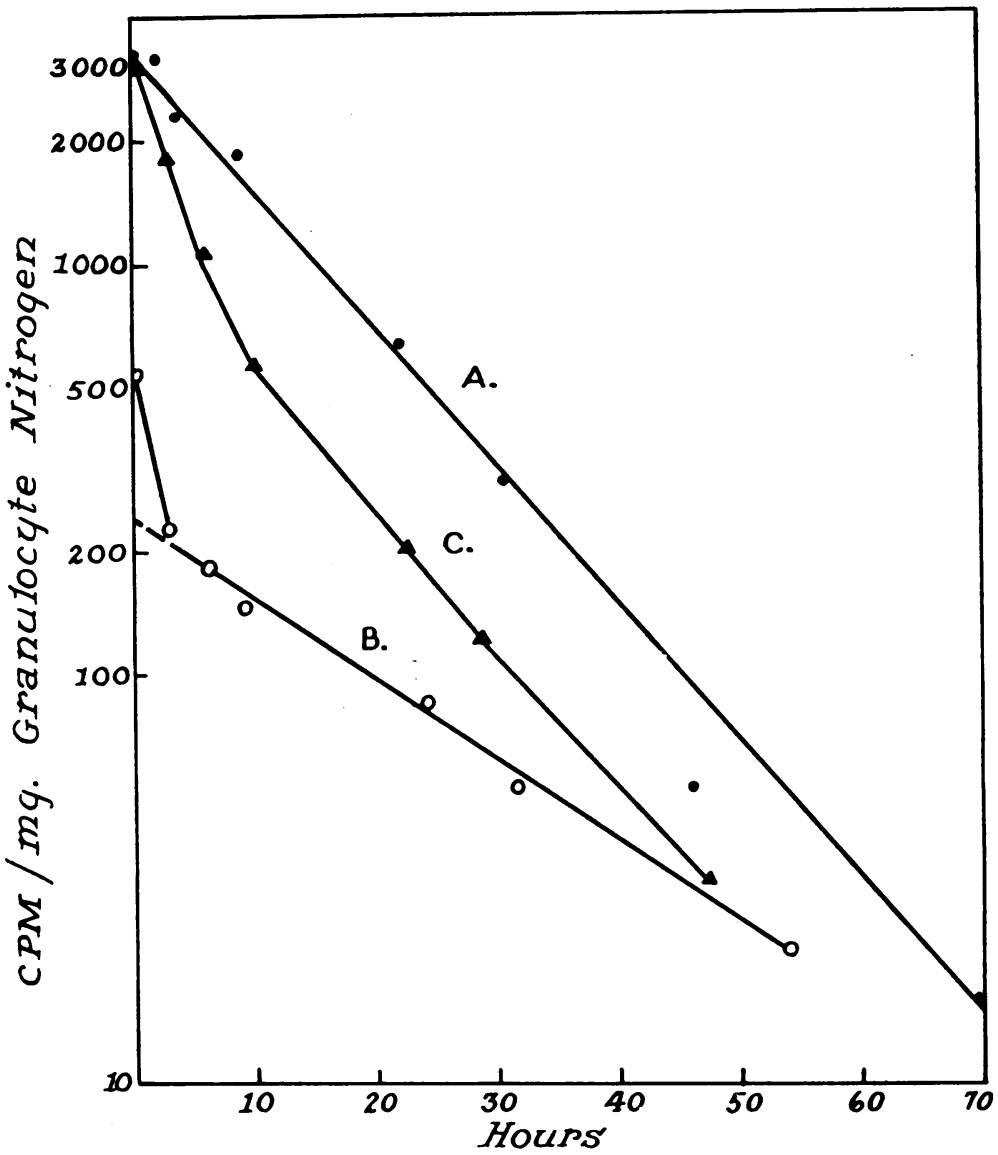

Fig. 1. Representative examples of the three tYPes of BLOOD GRANULOCYTE DISAPPEARANCE CURVES OBSERVED IN PATIENTS WITH NEUTROPHILIC GRANULOCYTOSIS. Curve $A$ is the single exponential disappearance curve usually obtained; note that the "determined" and "extrapolated" to values are the same. Curves $B$ and $C$ were encountered less frequently. In the $B$ curves the extrapolated to value is considerably lower than the determined to value. 
TABLE I

Incidence of the several types of curves in normal and diseased subjects

\begin{tabular}{|c|c|c|c|c|}
\hline Normal & $\begin{array}{c}\text { Total } \\
\text { studies } \\
59\end{array}$ & $\underset{56}{\text { Curve A }}$ & Curve B & $\underset{3}{\text { Curve } C}$ \\
\hline $\begin{array}{l}\text { Polycy themia vera } \\
\text { Infection } \\
\text { Miscellaneous conditions } \\
\text { Myelofibrosis }\end{array}$ & $\begin{array}{r}16 \\
17 \\
20 \\
7\end{array}$ & $\begin{array}{r}11 \\
11 \\
14 \\
5\end{array}$ & $\begin{array}{l}3 \\
2 \\
5 \\
2\end{array}$ & $\begin{array}{l}2 \\
4 \\
1 \\
0\end{array}$ \\
\hline Total & 60 & 41 & 12 & 7 \\
\hline
\end{tabular}

Only the determined TBGP values are given in the tables since they are the more accurate, as will be discussed.

Normal subjects. The mean granulocyte kinetic values obtained in 56 normal subjects are summarized in Table II for ready reference. These data were selected from 66 complete blood granulocyte kinetic studies carried out on apparently normal subjects. Seven of the 66 studies were discarded because the subjects were found to have granulocyte counts outside the $95 \%$ limits of normal as given by Osgood and co-workers (7). In 56 of the remaining 59 normal subjects the BGSA curve followed a single exponential decline. In three subjects a BGSA curve with a changing dis- appearance rate (Figure 1, curve C) was encountered.

Polycythemia rubra vera. TBGP values ranging from normal to 12 times the normal mean were encountered in patients with polycythemia vera (Table II). In all 13 studies on patients with granulocytosis the TBGP was larger than normal. In one of the three patients with normal blood granulocyte concentration the TBGP was also larger than normal. The correlation between the blood granulocyte concentration and determined TBGP size was good $(\mathrm{r}=+0.85, \mathrm{p}=<0.001)$. In addition, at increased TBGP values the size of the MGP was enlarged to a greater degree than was the CGP. As a result, the CGP/TBGP ra-

TABLE II

Blood granulocyte kinetic values in patients with polycythemia vera as compared to normal subjects*

\begin{tabular}{|c|c|c|c|c|c|c|}
\hline Study no. & G & TBGP & CGP & $t_{1}$ & GTR & $\begin{array}{l}\text { Type of } \\
\text { curve }\end{array}$ \\
\hline & per $\mathrm{mm}^{\mathbf{3}}$ & \multicolumn{2}{|c|}{$\times 10^{7} \mathrm{G} / \mathrm{kg}$} & hrs & G/kg/day $\times 10^{7}$ & \\
\hline $\begin{array}{l}\text { Mean } 56 \text { normals } \\
95 \% \text { limits }\end{array}$ & $\begin{array}{c}4,650 \\
2,250-6,600\end{array}$ & $\begin{array}{c}62.5 \\
14-108\end{array}$ & $\begin{array}{r}31.4 \\
19-44\end{array}$ & $\begin{array}{r}6.7 \\
4-10\end{array}$ & $\begin{array}{c}163 \\
50-340\end{array}$ & \\
\hline \multicolumn{7}{|l|}{ Polycy themia vera (16) } \\
\hline $\begin{array}{c}\text { IV-166 } \\
\text { V-34 } \\
\text { III-6 } \\
\text { IV-36 } \\
\text { V-178 } \\
\text { V-140 } \\
\text { VI-32 } \\
\text { VI-80 } \\
\text { V-122 } \\
\text { IV-94 } \\
\text { V-144 } \\
\text { IV-62 } \\
\text { VII-58 } \\
\text { V-32 } \\
\text { IV-124 } \\
\text { VI-74 }\end{array}$ & $\begin{array}{r}23,900 \\
21,400 \\
20,830 \\
19,300 \\
13,973 \\
13,300 \\
12,700 \\
12,000 \\
11,910 \\
11,540 \\
10,340 \\
9,540 \\
8,325 \\
6,190 \\
5,030 \\
5,000\end{array}$ & $\begin{array}{r}610 \\
805 \\
513 \\
411 \\
429 \\
238 \\
189 \\
379 \\
204 \\
397 \\
175 \\
316 \\
139 \\
272 \\
104 \\
52\end{array}$ & $\begin{array}{l}154 \\
161 \\
171 \\
137 \\
85 \\
98 \\
85 \\
126 \dagger \\
87 \\
109 \dagger \\
71 \dagger \\
72 \\
50 \\
42 \dagger \\
55 \dagger \\
45\end{array}$ & $\begin{aligned} 11.0 \\
\\
9.5 \\
14.2 \\
11.3 \\
7.8 \\
9.3 \\
10.5 \\
9.2 \\
11.2 \\
9.0 \\
15.5 \\
8.0 \\
15.0 \\
\\
7.4\end{aligned}$ & $\begin{array}{l}923 \\
\\
899 \\
498 \\
631 \\
503 \\
336 \\
600 \\
367 \\
582 \\
323 \\
340 \\
291 \\
302\end{array}$ & $\begin{array}{l}\text { A } \\
\text { C } \\
\text { A } \\
\text { A } \\
\text { B } \\
\text { A } \\
\text { A } \\
\text { A } \\
\text { A } \\
\text { A } \\
\text { A } \\
\text { B } \\
\text { A } \\
\text { B } \\
\text { C } \\
\text { A }\end{array}$ \\
\hline
\end{tabular}

* $\mathrm{G}=$ granulocytes; TBGP = total blood granulocyte pool; CGP = circulating granulocyte pool; GTR = granulocyte turnover rate.

$\dagger$ These CGP values were calculated from $\mathrm{Cr}^{51}$ blood volume values determined at the completion of the study. 


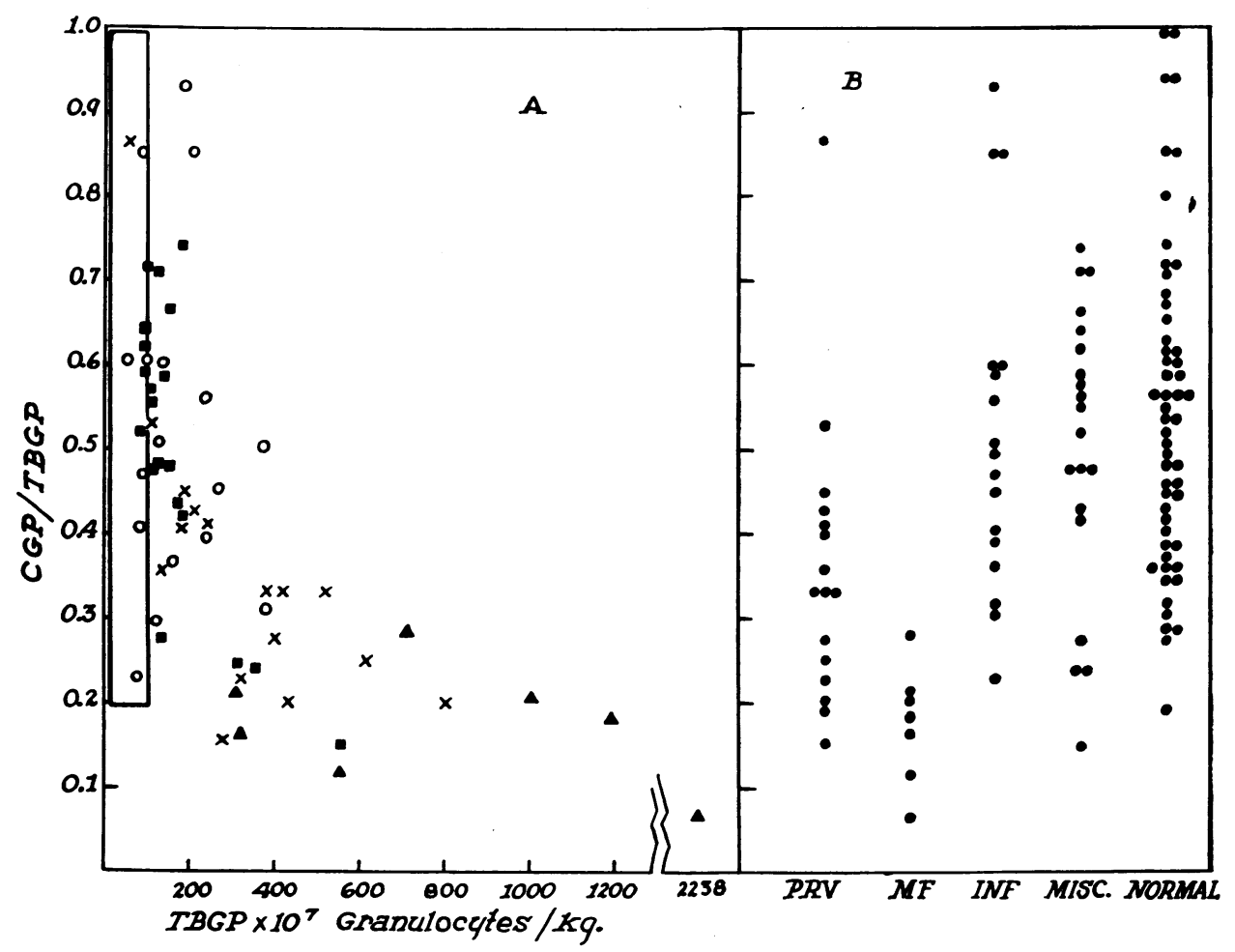

Fig. 2. A. RELATIONSHIP BetWeEN THE PROPORTION OF GRANULOCYTES IN THE TBGP THAT ARE CIRCULATING, AS REPRESENTED BY THE CIRCULATING GRANULOCYTE POOL/TOTAL BLOOD GRANULOCYTE POOL (CGP/TBGP) RATIO, AND THE TBGP SIZE IN 60 STUdIES ON PATIENTS WITH DISEASE AS COMPARED TO NORMAL SUBJECTS. The rectangle encompasses $95 \%$ of normal studies. Patients with polycythemia vera $=X$. Patients with infection $=0$. Patients with miscellaneous disorders $=\mathbf{a}$. Patients with myelofibrosis $=\mathbf{A}$. B. Comparison of the Distribution OF CELLS IN THE TBGP OF PATIENTS WITH DISEASE AS COMPARED TO NORMAL SUBJECTS, AS INDICATED BY THE RATIO CGP/TBGP. PRV = polycythemia rubra vera. MF= myelofibrosis. INF $=$ infection. MISC. $=$ miscellaneous diseases.

tio was less than 0.45 in all 13 subjects with granulocytosis (Figure 2, A and B). When the TBGP was enlarged, the GTR was usually increased (Figure 3 ) while the $t_{1}$ remained normal or was only moderately prolonged (Figure 4 ).

Infection. In the 17 patients with subacute to chronic infections determined TBGP values ranging from normal to six times the normal mean were encountered. In ten of the eleven patients with granulocytosis the TBGP was larger than normal (Table III). Only one patient with a normal granulocyte count had a slightly enlarged TBGP; presumably the count was normal due to a shift of cells to marginal sites. The correlation between blood granulocyte concentration and determined TBGP size was good $(r=+0.74$, $\mathrm{p}=<0.001)$. The distribution of cells between circulating and marginal sites varied considerably and was similar to the distribution encountered in normal subjects (Figure 2B). The $t_{t}$ remained normal or was moderately prolonged in all of the patients with infection. In no instance was the $t_{1}$ shorter than normal (Table III). When the TBGP was enlarged the GTR was usually also increased, but there was considerable overlap with the normal range of values (Figure 3 ). GTR values in these patients with subacute and chronic infections did not exceed twelve times the normal mean.

Miscellaneous diseases. In most of the 20 studies carried out on patients with a variety of diseases only modest elevations in granulocyte concentration were noted (Table IV). The TBGP was also either normal or only moderately elevated 


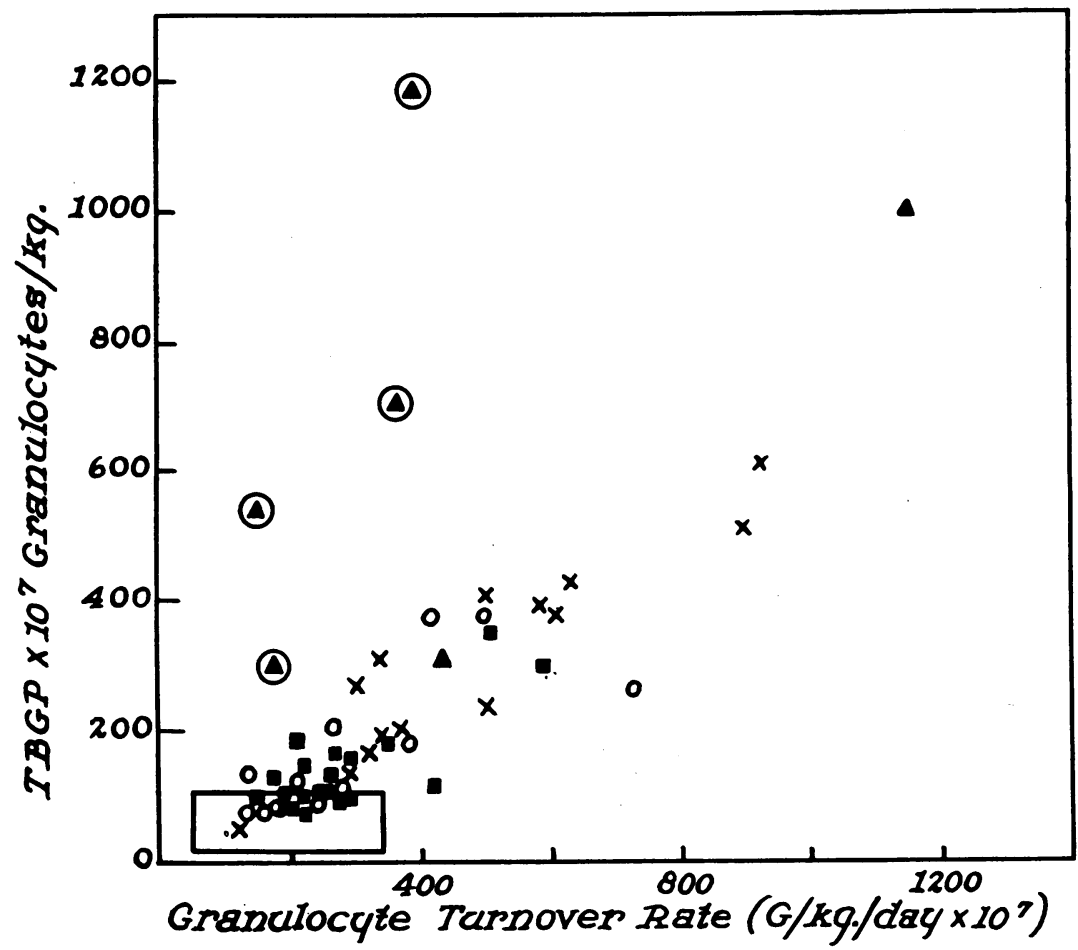

Fig. 3. Relationship BETWEen TBGP SIZE AND the GRANULOCyte turNover RAte (GTR) IN 60 studies on Patients with DISEASE. The rectangle encompasses $95 \%$ of normal subjects. 'Patients with polycythemia vera $=\times$. Patients with infection $=0$. Patients with miscellaneous disorders $=\mathbf{a}$. The first three myelofibrosis studies in Table $\mathrm{V}$ are designated by $\boldsymbol{\Delta}$; the last four studies are designated by (A). The second study on Patient II-236, Table V, is not included because of the very large values: $\mathrm{TBGP}=2,238, \mathrm{GTR}=1,987$.

TABLE III

Blood granulocyte kinetic values in patients with infection*

\begin{tabular}{|c|c|c|c|c|c|c|c|}
\hline Study no. & Diagnosis & G & TBGP & CGP & $t_{1}$ & GTR & $\begin{array}{c}\text { Type of } \\
\text { curve }\end{array}$ \\
\hline & & per $m m^{3}$ & \multicolumn{2}{|c|}{$\times 10^{7} \mathrm{G} / \mathrm{kg}$} & hrs & $\begin{array}{c}G / \mathrm{kg} / \mathrm{day} \\
\times 10^{7}\end{array}$ & \\
\hline I-161 & Empyema & 30,100 & 208 & 177 & 13.0 & 267 & A \\
\hline VII-78 & Perisplenic abscess & 23,770 & 182 & 169 & 8.0 & 378 & A \\
\hline IV-2 & Cholecystitis-subacute & 23,370 & 373 & 187 & 15.0 & 414 & A \\
\hline I-157 & Lung abscess & 17,780 & 373 & 115 & 12.5 & 496 & A \\
\hline VII-84 & $\mathrm{Ca}$ of lung with abscess & 17,690 & 232 & 130 & & & \\
\hline II-124 & Pyelonephritis & 16,600 & 262 & 118 & 6.0 & 727 & $\bar{A}$ \\
\hline VII-52 & Pneumonitis & 11,520 & 234 & 92 & & & C \\
\hline III-178 & Lung abscess-septicemia & 10,350 & 131 & 78 & 16.0 & 136 & A \\
\hline IV -66 & Colitis & 9,330 & 151 & 55 & & & \\
\hline VII-80 & Abscess of chest wall & 9,320 & 126 & 64 & 10.0 & 209 & A \\
\hline VII-86 & Genitourinary infection & 7,690 & 87 & 74 & 8.0 & 181 & B \\
\hline VII-12 & Diabetes, pneumonitis & 5,430 & 87 & 41 & 8.0 & 181 & $\overline{\mathbf{A}}$ \\
\hline VII-36 & Genitourinary infection & 6,720 & 98 & 59 & 6.8 & 240 & A \\
\hline I-168 & Genitourinary infection & 4,300 & 79 & 32 & 9.0 & 146 & A \\
\hline II-174 & Genitourinary infection & 4,180 & 119 & 35 & 7.1 & 280 & A \\
\hline IV-84 & Pyelonephritis & 3,790 & 48 & 29 & & & C \\
\hline VI-68 & Pyelonephritis & 2,200 & 74 & 17 & 8.0 & 154 & $\mathbf{B}$ \\
\hline
\end{tabular}

* See Table II for abbreviations. 


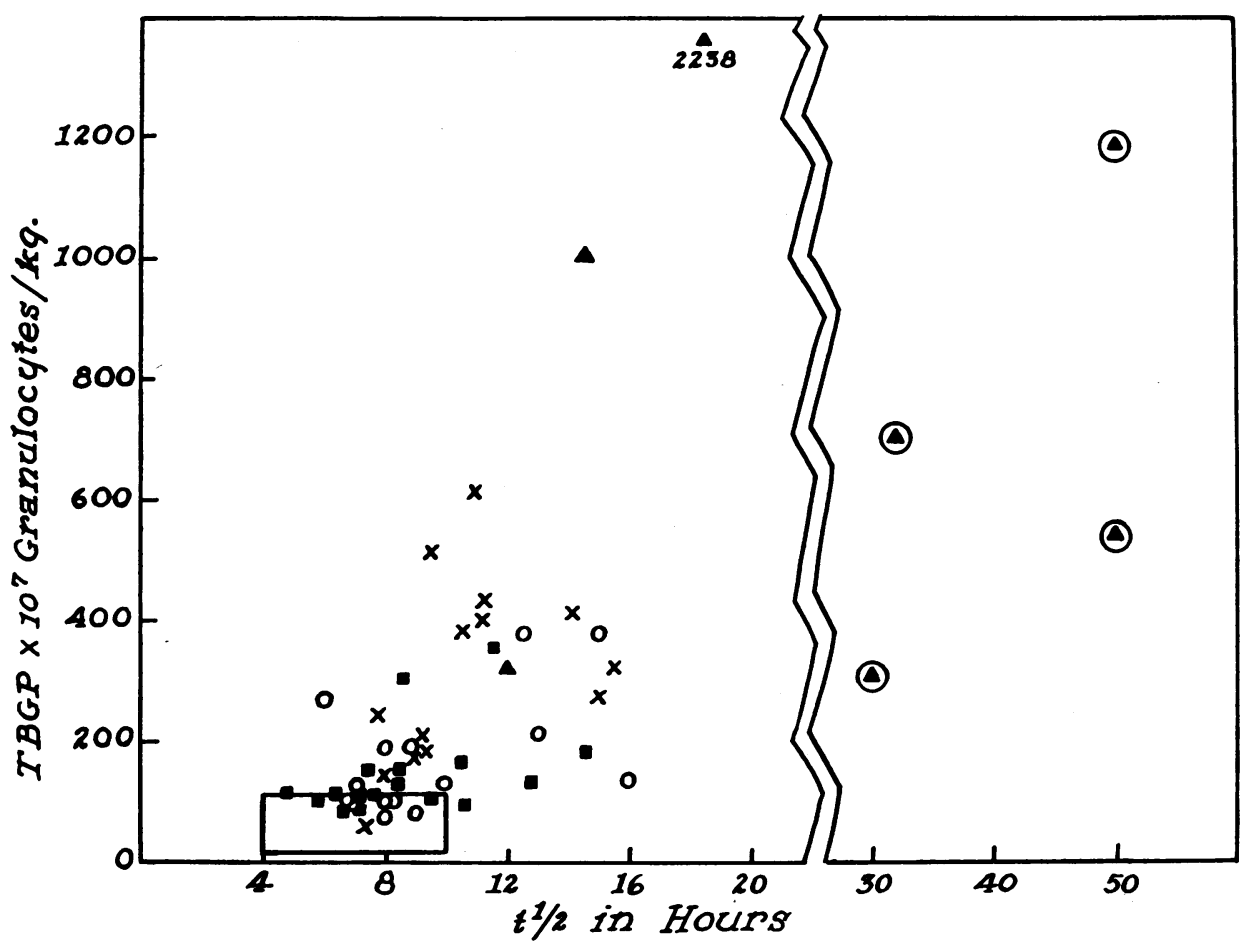

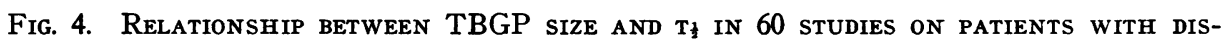
EASE. See Figure 3 legend for symbols. Note the change in scale on the abscissa between 20 and 30 hours.

TABLE IV

Blood granulocyte kinetics in patients with miscellaneous clinical conditions*

\begin{tabular}{|c|c|c|c|c|c|c|c|}
\hline Study no. & Diagnosis & G & TBGP & CGP & $\mathbf{t}_{\mathbf{3}}$ & GTR & $\begin{array}{c}\text { Type of } \\
\text { curve }\end{array}$ \\
\hline & & per $\mathrm{mm}^{3}$ & \multicolumn{2}{|c|}{$\times 10^{7} \mathrm{G} / \mathrm{kg}$} & hrs & $\begin{array}{c}G / \mathrm{kg} / \mathrm{day} \\
\times 10^{7}\end{array}$ & \\
\hline III-100 & Unexplained leukocytosis & 20,950 & 181 & 134 & 14.5 & 208 & A \\
\hline IV-162 & Hodgkin's disease & 12,840 & 146 & 97 & 7.6 & 218 & A \\
\hline V-160 & Unexplained leukocytosis & 12,100 & 348 & 84 & 11.5 & 503 & B \\
\hline III -40 & Hodgkin's disease & 11,760 & 187 & 79 & 9.0 & 345 & A \\
\hline $\mathrm{V}-174$ & Hodgkin's disease & 10,560 & 551 & 83 & & & C \\
\hline VI-150 & Unexplained leukocytosis & 10,450 & 303 & 73 & 8.6 & 586 & $\mathbf{B}$ \\
\hline IV -6 & Unexplained leukocytosis & 10,400 & 166 & 72 & 10.5 & 264 & A \\
\hline $\mathrm{V}-170$ & Laënnec's cirrhosis & 10,400 & 132 & 77 & 12.8 & 171 & A \\
\hline VII-24 & Unexplained leukocytosis & 9,890 & 101 & 72 & 7.0 & 239 & B \\
\hline VI-38 & Pulmonary infiltrate, unknown etiology & 9,500 & 107 & 76 & 6.4 & 278 & A \\
\hline VI-36 & Pulmonary coin lesion & 9,020 & 102 & 58 & $\begin{array}{l}0.4 \\
5.9\end{array}$ & 286 & $\hat{A}$ \\
\hline VI-160 & Unexplained leukocytosis & 8,840 & 110 & 61 & 7.5 & 243 & A \\
\hline VII-40 & Cushing's disease-adenoma & 8,500 & 148 & 71 & 8.5 & 290 & A \\
\hline $\mathrm{V}-176$ & Hodgkin's disease & 8,000 & 107 & 51 & 9.5 & 187 & B \\
\hline II-98 & Unexplained leukocytosis & 7,980 & 87 & 54 & 7.1 & 205 & A \\
\hline III-124 & Pulmonary infiltrate unknown etiology & 7,600 & 92 & 59 & 7.1 & 216 & A \\
\hline IV-170 & Giant follicular lymphoma & 7,540 & 94 & 55 & 10.6 & 148 & A \\
\hline II-210 & Hodgkin's disease & 6,850 & 86 & 45 & 6.6 & 217 & A \\
\hline VI-30 & Hodgkin's disease & 6,600 & 117 & 56 & 4.7 & 414 & $\mathrm{~B}$ \\
\hline $\mathrm{V}-38$ & Hodgkin's disease & 6,000 & 130 & 36 & 8.3 & 260 & A \\
\hline
\end{tabular}

* See Table II for abbreviations. 
TABLE $V$

Blood granulocyte kinetic values in patients with myelofibrosis*

\begin{tabular}{|c|c|c|c|c|c|c|c|c|c|c|c|c|}
\hline $\begin{array}{l}\text { Patient } \\
\text { no. }\end{array}$ & G & Myelo & Meta & Juv & Seg & TBGP & CGP & $t_{i}$ & GTR & $\begin{array}{l}\text { Type } \\
\text { of } \\
\text { curve }\end{array}$ & $\begin{array}{c}\text { Leukocyte } \\
\text { alkaline } \\
\text { phosphatase }\end{array}$ & $\begin{array}{l}\text { Fibrosis } \\
\text { on bone } \\
\text { marrow } \\
\text { biopsy }\end{array}$ \\
\hline & per $m m^{3}$ & $\%$ & $\%$ & $\%$ & $\%$ & \multicolumn{2}{|c|}{$\times 10^{7} \mathrm{G} / \mathrm{kg}$} & hrs & $\begin{array}{c}\text { G/ } / \mathrm{kg} / \text { day } \\
\times 10^{7}\end{array}$ & & & \\
\hline$\underset{\dagger}{\mathrm{II}-236}$ & $\begin{array}{l}30,660 \\
21,680\end{array}$ & 1.0 & $\begin{array}{l}2.5 \\
0.5\end{array}$ & $\begin{array}{l}35.0 \\
52.0\end{array}$ & $\begin{array}{l}54.0 \\
36.0\end{array}$ & $\begin{array}{r}999 \\
2,238\end{array}$ & $\begin{array}{l}208 \\
147\end{array}$ & $\begin{array}{l}14.5 \\
18.5\end{array}$ & $\begin{array}{l}1,146 \\
1,987\end{array}$ & $\begin{array}{l}\mathbf{A} \\
\mathbf{A}\end{array}$ & $\begin{array}{l}\text { NA } \\
271\end{array}$ & $\begin{array}{l}\text { NA } \\
\text { No }\end{array}$ \\
\hline III-122 & 8,000 & 2.5 & 4.5 & 24.5 & 50.0 & 314 & 52 & 12.0 & 435 & A & $186,204,192$ & Yes \\
\hline$V-46$ & 30,730 & 5.0 & 20.0 & 28.0 & 26.0 & 705 & 199 & 32.0 & 367 & B & 68 & No \\
\hline VI-40 & 27,600 & 5.0 & 17.5 & 29.0 & 32.0 & 1,184 & 218 & 50.0 & 394 & A & $107,17,28$ & Yes \\
\hline$V-158$ & 9,770 & 3.0 & 10.5 & 27.5 & 18.5 & 305 & 65 & 30.0 & 173 & A & 11,4 & Yes \\
\hline$\ddagger$ & 9,800 & 4.5 & 8.0 & 36.0 & 25.0 & 544 & 64 & 50.0 & 151 & B & $261,38,324$ & NA \\
\hline
\end{tabular}

* See Table II for abbreviations. Myelo = myelocytes; Meta = metamyelocytes; Juv = juvenile forms; Seg = segmented neutrophils, $\mathrm{NA}=$ not available.

$\dagger$ The second study was carried out 21 months after the first.

$\$$ The second study was carried out 2 years after the first.

in these patients. The correlation between determined TBGP and granulocyte concentration was poor in this group $(\mathrm{r}=+0.30, \mathrm{p}=<0.2)$, probably because of the narrow range of TBGP and granulocyte concentration values and the variation in distribution of granulocytes in the TBGP (Figure 2B). The $t_{1}$ values were normal or moderately prolonged in these patients, and the GTR values were within the normal range in all but four studies.

Myelofibrosis. Seven studies were carried out on patients thought to have myelofibrosis (Table V). The largest TBGP values encountered were in this group, and as with the other patients the large TBGP values were found in patients with high blood granulocyte counts. One distinguishing feature of the myelofibrosis patients was the marked shift of granulocytes into the MGP so that the CGP/TBGP ratio was less than 0.28 in all seven studies (Figure $2 \mathrm{~B}$ ).

The $t_{3}$ values were large in all patients with myelofibrosis but were so strikingly prolonged in four ( 30 to 50 hours) that granulocyte kinetics in these patients appear to be completely different from the findings in the other patients described (Figure 4). These patients were in every way similar to the others considered to have myelofibrosis except for the somewhat larger proportion of myelocytes and metamyelocytes in their blood. The net result of the large TBGP and the very long $t_{t}$ values in these four studies is a normal or only slightly increased GTR (Figure 3 ). The results in these four studies are similar to those encountered in patients with chronic myelocytic leukemia in relapse (3).

All groups combined. If all the data are examined together, several features are apparent. When the blood granulocyte concentration is increased, the TBGP size is usually increased also (Figure 5), and the correlation between these parameters is fairly good $(r=+0.60, p=<$ 0.001 ). At larger TBGP values the granulocytes were distributed unevenly between the CGP and the MGP. This is seen in Figure 2A where the CGP/TBGP ratio is compared with TBGP size. However, this impression may reflect the fact that most of the larger TBGP values were seen in patients with myelofibrosis and polycythemia vera.

In patients with infection the $t_{\frac{1}{2}}$ was normal or prolonged rather than shortened. This was also the case in the other disorders studied (Figure 4). The longest $t_{1}$ encountered in any of these patients (excluding the four myelofibrosis studies in which $t_{1}$ values were long) was 18.5 hours. No patient had a $t_{1}$ value less than normal. The correlation between TBGP size and $t_{\frac{1}{2}}$ was $+0.59(p=<0.001)$. The four studies in patients with myelofibrosis in whom the $t_{t}$ values were long were excluded from this calculation.

The excellent correlation between TBGP size and GTR can be seen in Figure $3(r=+0.95$, $p=<0.001)$. The four studies in myelofibrosis in which very long $t_{t}$ values were observed were again excluded since they do not appear to belong to the same population (Figure 3 ). 


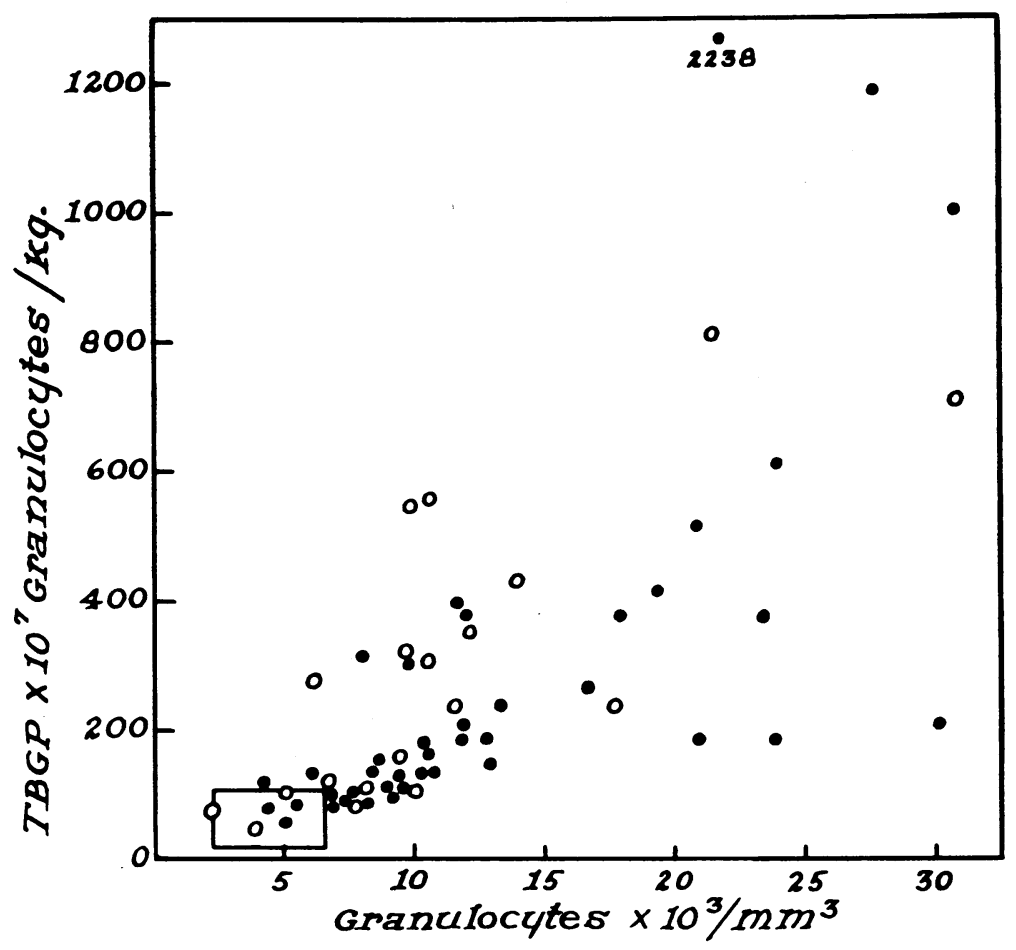

Fig. 5. Relationship betweEn the SIze OF the TBGP aNd the bloOd GRANULOCYTE COUNT IN 60 STUDIES ON PATIENTS WITH POLYCYTHEMIA RUBRA VERA, CHRONIC INFECTION, MYELOFIBROSIS, OR ONE OF A NUMBER OF OTHER MISCELLANEOUS CONDITIONS STUDIED. The solid dots (O) indicate values obtained from type A curves. The circles $(O)$ indicate values calculated from determined $t_{0}$ values in patients with type $B$ and $C$ curves. The rectangle includes $95 \%$ of normal subjects.

\section{Discussion}

Because of the close similarity in granulocyte kinetic findings in the various disorders studied, they will be discussed as a whole except for the four studies in patients with myelofibrosis which differed from the remainder. These will be considered separately.

From the relationship between TBGP size and granulocyte count shown in Figure 5 it can be seen that, as the blood granulocyte count increased, the TBGP also increased $(r=+0.60$, $p=<0.001)$. As the TBGP increased, the $t_{1}$ remained normal or became prolonged but never decreased (Figure 4). Finally, as the TBGP increased the GTR increased (Figure 3$) \quad(r=$ $+0.95, \mathrm{p}=<0.001)$. All three of these relationships appear to be continuous, with no clear segregation of values by disease type. These data may be reviewed for possible clues as to the physiologic mechanisms controlling granulocyte behavior in pathologic states.

The findings of greatest interest were the normal or slightly prolonged $t_{\frac{1}{2}}$ values encountered in all patients studied and the excellent correlation between the blood GTR and the size of the TBGP.

GTR values in these patients ranged from normal to 14 times normal. Since the disappearance of granulocytes from the circulation of normal subjects has been demonstrated to be a first order process (2), one would expect the turnover of cells to depend on the number present in the blood (TBGP). However, from the formula for calculation of the GTR [GTR $=0.693$ $\times$ TBGP $\times 24$ (hours) $/ t_{1}$ (hours) $]$ it can be seen that an increase in GTR could result from an increase in fractional turnover rate (i.e., a short $t_{z}$ ) as well as from an increase in TBGP size or from certain combinations of these two 
parameters. The absence of an increase in fractional turnover rate (short $t_{\frac{1}{2}}$ ) in any of these studies suggests that it is unusual for the GTR to be increased by this means. The major factor influencing GTR in these patients appeared to be the size of the TBGP.

The accumulation of large numbers of neutrophils at sites of injury and inflammation is a common clinical occurrence. Therefore, it is of interest that in patients with extensive purulent processes (Patients VII-78, I-157, and III-178 in Table II) the GTR may be only one to three times the normal mean. Since large but unknown numbers of granulocytes accumulate in and are discharged from such areas of inflammation, larger GTR might have been anticipated. However, it must be kept in mind that the GTR represents the total blood granulocyte turnover per day. Since the normal mechanisms and sites of blood granulocyte removal are largely unknown, it is quite possible that under appropriate conditions a marked reduction in clearance of granulocytes through normal channels and a shift of these cells to the site of injury may occur, thus providing many times the normal number of cells to an injured tissue with little increase in GTR. For example, if we assume a 5 to $10 \%$ clearance of granulocytes in the normal lung (8), it seems quite possible that with the development of pneumonia, the lung clearance fraction could be increased greatly, perhaps to 70 or even $80 \%$. Such a change would increase the cells removed by the lung seven- or eightfold without any increase in over-all GTR. If the GTR were simultaneously increased threefold, more than a twentyfold increase in the number of cells accumulated in the lung would result. Such a scheme could explain the rather modest increase in GTR encountered in patients with extensive purulent infections and is compatible with the demonstration by Allison, Smith, and Wood that neutrophils selectively accumulate at sites of tissue injury (9).

The slightly prolonged $t_{\frac{1}{2}}$ encountered in some of these patients seems related to the size of the TBGP (Figure 4). It has not been possible to demonstrate a relationship between the prolonged $t_{1}$ noted in some of them and the presence of slightly increased numbers of myelocytes and metamyelocytes in their blood. This may be due to the lack of any relationship between these two parameters or to the limited number of these immature cells (less than $11.5 \%$ ) in the blood of the patients studied. The markedly prolonged $t_{1}$ values in four of the patients thought to have myelofibrosis have already been mentioned. The prolonged $t_{\frac{1}{2}}$ values and the increased number of immature cell forms present in their blood are similar to the findings in patients with chronic myelocytic leukemia in relapse (3). The possible explanations for the markedly prolonged $t_{\frac{1}{2}}$ in such patients have been discussed (3). Some factor in addition to enlarged TBGP size must be invoked to explain the marked divergence of these four studies (Figure 4) from the findings in other patients studied. This factor is presumed to be the presence of immature cell forms in the blood. In any case, it is apparent that leukokinetic studies do not differentiate some patients with what appears to be myelofibrosis from patients whose findings are those of classical chronic myelocytic leukemia.

In 40 of 48 studies carried out on patients with a stable, persistent granulocytosis the TBGP was enlarged, and in all subjects with a granulocytosis greater than 10,000 per $\mathrm{mm}^{3}$ the TBGP was enlarged. In 8 of 16 studies on patients with normal TBGP, elevated granulocyte counts were encountered. It is possible that these 8 studies represent a clinical counterpart to previously reported experimental situations in normal subjects in whom a transient intravascular shift of cells from the MGP to the CGP resulted in a granulocytosis in the presence of a normal TBGP (1). Three patients with larger than normal TBGP but normal granulocyte counts were also encountered. That such intravascular shifts of cells would be seen in disease states in which fever, tachycardia, and alterations in blood flow and viscosity occur seems likely. However, since even in normal subjects there was wide variation in the distribution of granulocytes between the MGP and CGP with from 19 to $99 \%$ of the cells circulating in the CGP (Figure 2B), proof that a persistent granulocytosis may result from an altered distribution of cells is difficult to obtain. From Figure 2A it might be inferred that a shift of cells from the CGP to the MGP occurs with increasing TBGP size. However, this conclusion 
may not be valid since the largest TBGP values were found in patients with myelofibrosis and polycythemia vera. A TBGP larger than 400 $\times 10^{7}$ granulocytes per $\mathrm{kg}$ was seldom encountered in the other diseases studied. Only in patients with myelofibrosis does it seem clear that a shift of granulocytes into the MGP occurs regularly (Figure 2B). A lesser shift of granulocytes may be characteristic of patients with polycythemia vera, but this was not clearly demonstrated in the small group studied. When the blood granulocyte concentration and TBGP values were compared, the correlation between these two parameters was fairly good $(r=+0.60, p=<$ 0.001 ). The divergence of occasional values from the main group (Figure 2) is probably due to intravascular shifts of cells.

A significant proportion of the granulocyte radioactivity curves in these patients did not follow a single exponential line (types $\mathrm{B}$ and $\mathrm{C}$, Figure 1). Type B curves appear to reflect the presence of damaged cells in the labeled, infused blood (3). The damaged cells are removed from the blood within several hours of infusion, whereas the undamaged cells remain. The finding that in subjects with type B curves the TBGP calculated from determined $t_{o}$ values is usually compatible with the granulocyte count (Figure 5) whereas the TBGP calculated from extrapolated $t_{o}$ values is unusually large is consistent with this interpretation. The same phenomenon was seen in patients with chronic myelocytic leukemia (3). Type C curves may also reflect cell damage. However, no such curves were encountered in studies in which cells were intentionally damaged and then infused (3). Therefore it seems more likely that these curves reflect a nonsteady state that is not evident in the blood granulocyte concentration values. In favor of this interpretation is the finding that in patients in whom skin inflammations were produced, type $\mathrm{C}$ curves were common (10).

\section{Summary}

Sixty studies of blood granulocyte kinetics have been carried out by means of the in vitro, diisopropyl fluorophosphate $\left(\mathrm{DFP}^{32}\right)$-labeled granulocyte technic in patients with polycythemia rubra vera, subacute and chronic infection, myelofibrosis, and miscellaneous diseases. The results are compared with values in 56 normal subjects. An increase in total blood granulocyte pool size was observed in all subjects with blood granulocyte counts persistently greater than 10,000 per $\mathrm{mm}^{3}$. In 8 of 16 patients with normal total blood granulocyte pools (TBGP) the granulocyte count was moderately elevated (7,500 to 9,890) and in three patients with moderately elevated TBGP the granulocyte concentration was within normal limits. These last two groups of studies presumably reflect intravascular shifts in granulocyte distribution.

In patients with myelofibrosis and in some patients with polycythemia rubra vera there was a tendency for the granulocytes to accumulate disproportionately in marginal sites, and this tendency was particularly noticeable when the total blood granulocyte pool values were high.

In all but four of the 60 studies the $t_{1}$ values were normal or moderately increased. In no study was the $t_{\frac{1}{2}}$ less than normal. The daily granulocyte turnover rate ranged from normal to twelve times normal. The increase in granulocyte turnover rate in these studies appears to be associated with an increase in the size of the blood granulocyte pool rather than an accelerated blood granulocyte pool renewal rate.

In four studies on patients with myelofibrosis very long $t_{1}$ values of 30 to 50 hours were found. These values are comparable to those encountered in patients with chronic myelocytic leukemia in relapse.

\section{Acknowledgments}

We gratefully acknowledge the capable technical assistance of Doris Kurth, Joyce Rose, June Hudson, Vreni Oberholzer, and Anne B. Stryjewski.

\section{References}

1. Athens, J. W., S. O. Raab, O. P. Haab, A. M. Mauer, H. Ashenbrucker, G. E. Cartwright, and M. M. Wintrobe. Leukokinetic studies. III. The distribution of granulocytes in the blood of normal subjects. J. clin. Invest. 1961, 40, 159.

2. Mauer, A. M., J. W. Athens, H. Ashenbrucker, G. E. Cartwright, and M. M. Wintrobe. Leukokinetic 
studies. II. A method for labeling granulocytes in vitro with radioactive diisopropylfluorophosphate $\left(\mathrm{DFP}^{22}\right)$. J. clin. Invest. 1960, 39, 1481.

3. Athens, J. W., S. O. Raab, O. P. Haab, D. R. Boggs, H. Ashenbrucker, G. E. Cartwright, and M. M. Wintrobe. Leukokinetic studies. X. Blood granulocyte kinetics in chronic myelocytic leukemia. J. clin. Invest. 1965, 44, 765.

4. Athens, J. W., A. M. Mauer, S. O. Raab, O. P. Haab, and G. E. Cartwright. Studies of granulocyte kinetics. J. clin. Invest. 1960, 39, 969.

5. Cartwright, G. E., J. W. Athens, O. P. Haab, S. O. Raab, D. R. Boggs, and M. M. Wintrobe. Blood granulocyte kinetics in conditions associated with granulocytosis. Ann. N. Y. Acad. Sci. 1964, 113, 963.

6. Athens, J. W., O. P. Haab, S. O. Raab, A. M. Mauer, H. Ashenbrucker, G. E. Cartwright, and M. M. Wintrobe. Leukokinetic studies. IV. The total blood, circulating and marginal granulocyte pools and the granulocyte turnover rate in normal subjects. J. clin. Invest. 1961, 40, 989.

7. Osgood, E. E., I. E. Brownlee, M. W. Osgood, D. M. Ellis, and W. Cohen. Total differential and absolute leukocyte counts and sedimentataion rates for healthy persons 19 years of age and over. Arch. intern. Med. 1939, 64, 105.

8. Ambrus, C. M., and J. L. Ambrus. Regulation of the leukocyte level. Ann. N. Y. Acad. Sci. 1959, 77, 445.

9. Allison, F., Jr., M. R. Smith, and W. B. Wood, Jr. Studies on the pathogenesis of acute inflammation. I. The inflammatory reaction to thermal injury as observed in the rabbit ear chamber. J. exp. Med. 1955, 102, 655.

10. Boggs, D. R., J. W. Athens, G. E. Cartwright, and M. M. Wintrobe. Masked granulocytosis. Proc. Soc. exp. Biol. (N. Y.), in press. 